\title{
AVALIAÇÃO DOS PROCEDIMENTOS DE HIGIENIZAÇÃO DOS BRINQUEDOS INFANTIS E DAS BRINQUEDOTECAS NACIONAIS
}

Paula Fernandes CHADI ${ }^{1}$

Ana Carolina Braz GARCIA ${ }^{2}$

Gabriela Corrêa CARVALHO ${ }^{3}$

Rafaela Aparecida PRATA 4

Ione CORRÊA ${ }^{5}$

\author{
${ }^{1}$ Enfermeira. Doutoranda do Programa de Pós-Graduação em Enfermagem pela Faculdade de Medicina da Universidade Estadual \\ Paulista-UNESP, Distrito Rubião Júnior, s/n. Brasil. email: pchadi@ hotmail.com.br \\ ${ }^{2}$ Enfermeira. Doutoranda do Programa de Pós - Graduação em Saúde na Comunidade pela Universidade de São Paulo- Campus de \\ Ribeirão Preto. \\ ${ }^{3}$ Graduanda em Farmácia pela Universidade Federal de Mato Grosso do Sul. Cidade Universitária. Universitário. CEP 79070-900. \\ Campo Grande, Brasil. e-mail gabrielacarvalho57@ yahoo.com
}

${ }^{4}$ Enfermeira. Mestranda do Programa de Pós-Graduação em Enfermagem pela Faculdade de Medicina da Universidade Estadual Paulista-UNESP, Distrito Rubião Júnior, s/n. Brasil. email: rafaela17prata@hotmail.com

${ }^{5}$ Enfermeira. Doutora. Professora no Programa de Pós Graduação pelo Departamento de Enfermagem da Faculdade de Medicina da Universidade Estadual Paulista-UNESP, Distrito Rubião Júnior, s/n Brasil. email: icorrea@ fmb.unesp.br

Subsidiado pela Fundação de Apoio a Pesquisa do Estado de São Paulo(FAPESP)

Recebido em: 30/05/2014 - Aprovado em: 15/09/2014 - Disponibilizado em: 15/12/2014

\begin{abstract}
RESUMO
As políticas de humanização viabilizam a tentativa dos profissionais da saúde de amenizar a hostilidade do ambiente hospitalar com objetos do convívio da criança, como por exemplo, seu brinquedo favorito. Esta medida tem sido cautelosa, uma vez que a autorização da entrada do brinquedo no ambiente hospitalar necessita de investigação em relação aos riscos de transmissão de microrganismos, natureza do material do qual é confeccionado o brinquedo e, conseqüentemente, se é passível de limpeza e desinfecção. Apesar de sua grande importância, o brinquedo/brinquedo terapêutico, pode ser um veículo de transmissão de microrganismos na unidade de recreação. O objetivo deste trabalho foi avaliar os procedimentos de higienização dos brinquedos infantis e das brinquedotecas nacionais. Trata-se de um estudo quantitativo, realizado com os enfermeiros sócios da Sociedade Brasileira de Enfermeiros Pediatras e Neonatais que atuam em área pediátrica em ambiente hospitalar. A amostra ficou constituída de 30 enfermeiros, dos quais 17 estavam vinculados á área hospitalar, um à área ambulatorial e 12 à atenção básica de saúde. Sendo 13 hospitais possuírem brinquedotecas. Quanto o predomínio de a composição dos brinquedos, houve predomínio nos de plástico. Sobre o produto de higienização apenas um dos enfermeiros responderem esse item que fazem a higienização com água e sabão seguido de álcool 70\%.Conclui-se a necessidades de novas investigações com numero maior de participantes para ter uma padronização dos métodos de higiene de acordo com a composição de o brinquedo no ambiente hospitalar. Palavras-chave: Higienização, Brinquedos, Brinquedoteca, Crianças, Desinfecção.
\end{abstract}

\begin{abstract}
The humanization policies attempt to enable health professionals to ease the hostility of the hospital with the child living objects, such as their favorite toy. This measure has been cautious since the release of Toy entering the hospital needs investigation in relation to the risks of transmission of microorganisms, the nature of the material it is made the toy and, consequently, it is capable of cleaning and disinfecting. Despite its great importance, the toy / therapeutic play, can be a vehicle of transmission of microorganisms in unit recreation. The aim of this study was to evaluate the cleaning procedures of the national children's toys and playrooms. This is a quantitative study among nurses members of the Brazilian Society of Pediatrics and Neonatal Nurses who work in pediatrics in the hospital. The sample consisted of 30 nurses, 17 of which were tied to area hospitals, one ambulatory area and 12 to basic health care. Being 13 hospitals possess playrooms. As the dominance of the composition of toys predominated in plastic. About the product hygiene only one of this item that nurses respond do the cleaning with soap and water followed by $70 \%$ alcohol to. Conclueds needs further investigations with larger number of participants to have a standard of hygienic methods in accordance with the composition of the toy in the hospital environment.
\end{abstract}

Keywords: Hygiene, Toys, Toy, Children, Disinfection 


\section{INTRODUÇÃO}

Nos últimos tempos, a atenção dos pesquisadores e profissionais da área da saúde tem sido direcionada à medicina preventiva que, na realidade, demanda menos tempo de trabalho, é menos onerosa e, principalmente, proporciona maior benefício à população. A preocupação com este assunto é evidente e incumbe-se ao enfermeiro grande parte da responsabilidade, não só pela segurança do paciente e da equipe de saúde, como também pelo gerenciamento da unidade ${ }^{(1)}$.

Historicamente, a Enfermagem estabeleceuse como profissão no século $\mathrm{XIX}^{(2)}$. Tem suas bases científicas proposta por Florance Nightingale sendo influenciada diretamente por sua permanência em locais onde se executava o cuidado de forma leiga e fundamentado nos conceitos religiosos. Foi através dela que se iniciou o desenvolvimento de uma preparação formal e sistemática para a aquisição de conhecimento, e de um trabalho de natureza distinta daqueles realizados anteriormente. A partir daí, novas condições foram proporcionadas aos pacientes, uma vez que se começa a permitir a manutenção do organismo em condições de não adoecer ou de se recuperar de doenças, dando a enfermagem uma dimensão original: a de favorecer o processo reparativo com o uso de alimentos, higiene do ambiente e circulação do $\operatorname{ar}^{(3)}$.

Mesmo limitada por seu contexto histórico, visto que se trata de uma época prébacteriológica, Florence conseguiu desenvolver a prática com suporte epidemiológico para prevenção e controle de doenças infecciosas ${ }^{(4)}$. Contemporaneamente, Semmelweis em 1846, atuou na prevenção e na diminuição da infecção puerperal num hospital em Viena com o emprego da lavagem das mãos ${ }^{(4,5)}$.

$\mathrm{Na}$ segunda metade do século XIX as péssimas condições hospitalares podiam ser vistas de todos os ângulos. Nessa época, medidas foram implementadas a fim de tentar diminuir os riscos cirúrgicos como a invenção da autoclave (esterilização a calor úmido sob pressão) por Charles Chamberland, e por volta de 1880, à utilização das luvas de borracha flexível elaborada por William S. Halstead ${ }^{(2)}$.

A partir disso, iniciou-se a preocupação com o controle das infecções, o desenvolvimento da bacteriologia e suas conseqüentes aplicações: assepsia, anti-sepsia, desinfecção, esterilização e antibioticoterapia de forma mais aprimorada ${ }^{(2)}$.

Com respaldo do avanço bacteriológico, criou-se a necessidade de um "mundo asséptico", com a finalidade de alcançar o sucesso nos procedimentos invasivos cada vez mais especializados sobre o corpo humano. As áreas hospitalares e os artigos utilizados nos procedimento receberam a classificação segundo os riscos potenciais de transmissão de infecção para pacientes, os quais são: críticos, semi-críticos e não-críticos. Esta classificação direciona a escolha do processo de limpeza e de desinfecção destes materiais de forma coerente com seu uso ${ }^{(2)}$.

Pela abordagem histórica apresentada por diversos autores, a década de 50 foi caracterizada pelo inicio de uma nova era para 
as infecções relacionadas a assistência a saúde hospitalares e a epidemiologia ${ }^{(6,7)}$. Define-se Infecção hospitalar como aquela adquirida após a admissão do paciente ao hospital, que se manifestam durante a internação ou após a alta, quando a infecção está diretamente relacionada à internação ou procedimentos hospitalares, como cirurgias por exemplo ${ }^{(8)}$.

No Brasil, a preocupação com o controle de infecções hospitalares surge na década de 60 através de publicações dos primeiros relatos sobre o tema. A primeira iniciativa para criação de uma Comissão de Controle de Infecção Hospitalar data de 1963, no Hospital Ernesto Dornelhes, em Porto Alegre- $\mathrm{RG}^{(9)}$. A criação de comissões multidisciplinares, vinculadas a hospitais universitários, surgiram a partir da década de $70^{(9)}$.

As próximas décadas foram contempladas com a publicação do manual de Controle de Infecção Hospitalar, peloMinistério da Saúde ${ }^{(10)}$.

Em 1983, o Ministério da Saúde promulga a Portaria $\mathrm{n}^{\circ} 196$ de 24 de junho, determinando que todos os hospitais do país devessem manter Comissão de Controle de Infecção Hospital $(\mathrm{CCIH})$, independentes da natureza da entidade mantenedora. Nessas portarias, são enfatizadas as composições das $\mathrm{CCIH}$, suas atividades, as competências de seus membros, bem como algumas recomendações e indicadores epidemiológicos para o controle das infecções $(11,12,13)$. Esta determinação sem dúvida representou um avanço principalmente pelos propósitos pedagógicos e pela possibilidade de levar conhecimentos técnicos a todas as regiões e locais do território nacional ${ }^{(2)}$.

O controle de infecção hospitalar refere-se a todas as medidas que podem ser tomadas dentro de uma instituição hospitalar a fim de minimizar os riscos de viabilização de uma infecção por meio do ambiente hospitalar. Há três fatores importantes associados à ocorrência de infecção hospitalar, que são: os inerentes ao paciente, à agressão diagnóstica e terapêutica, e às condições do ambiente hospitalar. Enquanto considerados em conjunto determinam a instalação e/ou persistência da infecção, sua gravidade, sendo igualmente um auxilio na escolha da melhor forma de utilização das medidas de controle, em relação aos fatores inerentes $^{(14)}$.

No ambiente hospitalar, especificamente a amostragem da superfície do piso na unidade de internação pediátrica, quando coletado durante as 24 horas antecedentes ao procedimento de desinfecção, mostrou aumento do número de colônias microbianas durante período de maior atividade hospitalar: próximo das 8 e 16 horas ${ }^{(15)}$.

A unidade de internação pediátrica compreende a área de assistência desde o nascimento até a adolescência, uma faixa etária caracterizada por grandes transformações em função do crescimento e desenvolvimento do ser humano. A criança ao nascer apresenta adversidades referentes às novas condições de vida. Imaturidade das numerosas funções como nutritiva, imunitária, psíquica antes de nascer, e a necessidade de pô-las em exercício e de modo coordenado depois do nascimento, explica o porquê da maior vulnerabilidade à aquisição de 
doenças comparada ao adulto ${ }^{(16)}$.

$\mathrm{O}$ crescimento do ser humano necessita de estimulações para que os desenvolvimentos: físico, intelectual, emocional e social sejam desencadeados. O bebê, instintivamente explora seu corpo, o corpo da mãe, sons, cores e a partir destas brincadeiras se desenvolve, aprendendo muito do mundo extemo e intemo ${ }^{(17)}$.

Quando hospitalizada a criança desencadeia uma ruptura inevitável em sua vida cotidiana. A vivência da doença, da hospitalização e da realização de procedimentos diagnósticos e/ou terapêuticos pela criança, constituem-se experiências traumáticas e estressantes ${ }^{(18)}$.

$\mathrm{Na}$ vigência da hospitalização, a criança necessita ser estimulada/ incentivada na tentativa de minimizar os possíveis traumas psíquicos e perturbações no vínculo entre criança e familiares, uma vez que é afastada de sua vida cotidiana e do ambiente familiar. $\mathrm{O}$ confronto com a dor, a limitação física e a passividade, podem aflorar na criança sentimentos de culpa, punição emedo damorte ${ }^{(19)}$.

Segundo, o Estatuto da Criança e do Adolescente, Artigo 12 estabelece que o atendimento à saúde deva proporcionar condições para permanência em tempo integral de um dos pais ou responsáveis, nos casos de internação da criança ou adolescente ${ }^{(20)}$. Contudo, o enfermeiro ao planejar o cuidado deve respeitar a fase do desenvolvimento da criança e atender não só a ela como também sua família estabelecendo assim, um relacionamento terapêutico, o qual constitui-se em elemento central para um cuidado de enfermagem de qualidade ${ }^{(19)}$.

Brincar compreende o universo da própria criança; é uma oportunidade para seu desenvolvimento físico, cognitivo, emocional e social. Para a criança qualquer objeto pode ser visto como brinquedo, ou melhor, como material de seu interesse ${ }^{(21)}$. Brincar abrange ações de chupar, morder, chacoalhar, bater, jogar, ouvi. Na brincadeira a criança experiência papéis (re)construindo sua realidade, vivenciando sentimentos, comportamentos e fazendo representações do mundo exterior ${ }^{(22)}$.

Numa visão sócio-histórica, o brincar ocorre num contexto cultural, sendo impossível dissociar afeto e cognição, forma e conteúdo da ação humana. No espaço do brincar a criança expressam sentimentos, idéias, fantasias, interligando o real ao imaginário. Além disso, brincam também para dominar angústias e controlar idéias ou impulsos que conduzem as $\operatorname{mesmas}^{(23)}$.

Para amenizar estas experiências, é preciso compreender sua necessidade emocional. Dentre os recursos disponíveis podemos utilizar o brinquedo na assistência à criança tanto na sua função recreadora, como instrumento de comunicação, instrumento educativo e na sua função catártica, na qual se fundamenta o brinquedo terapêutico ${ }^{(23)}$.

Com isso, a atividade lúdica, isto é, a utilização do brinquedo no hospital, deve ser vista como instrumento terapêutico a serviço da intervenção médica, psicológica e de enfermagem, apresentando efeitos positivos além da recreação, uma vez que essa técnica 
consegue amenizar o sofrimento da situação de hospitalização ${ }^{(24)}$.

Segundo a resolução do COFEN $\mathrm{N}^{\circ}$ 295/2004 - Artigo $1^{\circ}$ - “compete ao enfermeiro que atua na área pediátrica; enquanto integrante da equipe multiprofissional de saúde, a utilização da técnica do Brinquedo/Brinquedo terapêutico, na assistência à criança e família hospitalizadas" (25).

A portaria $\mathrm{n}^{\circ} 2.261$, de 23 de novembro de 2005, aprova o regulamento que estabelece as diretrizes de instalação e funcionamento das brinquedotecas nas unidades de saúde que ofereçam o atendimento pediátrico em regime de internação ${ }^{(26)}$.

O tipo de brinquedo escolhido ou fornecido à criança pode ajudar em seu desenvolvimento em diversas áreas já citadas anteriormente a fim de permitir o uso prolongado sem causar riscos à saúde da criança visto que num hospital as interações entre pacientes são freqüentes. Isso pode se agravar em áreas comuns como sala de jogos, brinquedoteca onde há compartilhamento de materiais podendo acarretar em contaminação dos brinquedos com secreções, tornando-os veículo de transmissão de microrganismos ${ }^{(2)}$.

A transmissão de um microrganismo pode ocorrer de forma direta, indireta (veículo ou vetor) ou aérea. Veículo é qualquer objeto ou material inanimado que possa carrear o microorganismo como: talheres, alimentos, brinquedos $^{(2)}$, além das próprias mãos dos profissionais de saúde, as quais são veículos importantes na transmissão de microrganismos dentro do ambiente hospitalar ${ }^{(27,28,29)}$.

Os brinquedos e livros podem ser considerados artigos semi-críticos (todos aqueles que entram em contato com a mucosa íntegra do paciente) e não-críticos (todos aqueles que entram em contato com a pele íntegra do paciente) conforme sua utilidade ${ }^{(30)}$.

Estudos anteriores identificam a contaminação dos brinquedos por microrganismos e a ocorrência de infecções veiculadas por estes artigos em clínicas e hospitais ${ }^{(31,32,33,34,35)}$.

Atualmente, as políticas de humanização viabilizam a tentativa dos profissionais da saúde de amenizar a hostilidade do ambiente hospitalar com objetos do convívio da criança, como por exemplo, seu brinquedo favorito. Esta medida tem sido cautelosa, uma vez que a autorização da entrada do brinquedo no ambiente hospitalar necessita de investigação em relação aos riscos de transmissão de microrganismos, natureza do material do qual é confeccionado o brinquedo e, conseqüentemente, se é passível de limpeza e desinfecção. Apesar de sua grande importância, o brinquedo/brinquedo terapêutico, pode ser um veículo de transmissão de microrganismos na unidade de recreação ${ }^{(17)}$.

$\mathrm{Na}$ tentativa de conhecer como está sendo realizado o processo de higienização do brinquedo e das salas de atividades lúdicas, propomos-nos a realizar esta investigação com os enfermeiros que atuam em unidade de internação pediátrica. 


\section{OBJETIVO GERAL}

Avaliar os procedimentos de higienização dos brinquedos infantis e das brinquedotecas nacionais

\section{OBJETIVOS ESPECÍFICOS}

- Identificar o processo de higienização dos brinquedos;

- Identificar o processo de limpeza das salas de atividades recreativas;

- Analisar as facilidades e as dificuldades no processo de higienização do brinquedo/brinquedo terapêutico bem como o ambiente de recreação.

\section{TRAJETÓRIA METODOLOGIA}

Trata-se de um estudo quantitativo e sua análise foi realizada por estatística descritiva em que os dados foram demonstrados através de gráficos de frequiência ou parâmetros associados a essas distribuições ${ }^{(36)}$.

\section{População}

O estudo foi realizado com os enfermeiros sócios da Sociedade Brasileira de Enfermeiros Pediatras e Neonatais que atuam em área pediátrica em ambiente hospitalar.

Os hospitais representam um papel social, dentro do contexto da educação e da assistência á saúde, de inestimável relevância. Em se tratando de órgãos formadores de recursos humanos para atendimentos à população na relação saúde-doença, impõe-se à adoção de procedimentos e medidas condizentes com suas funções ${ }^{(37)}$.

\section{Coleta dos dados}

A coleta de dados foi realizada mediante o recebimento dos endereços dos sócios da Sociedade Brasileira de Enfermeiros Pediatras e Neonatais onde foi enviado o Termo de Consentimento Livre Esclarecido juntamente com o questionário via correio, após a aprovação pelo Comitê de Ética em Pesquisa da Faculdade de Medicina do Campus de Botucatu/UNESP. O questionário preenchido foi devolvido para análise, interpretação e preparação dos resultados, juntamente com o consentimento do profissional em participar da pesquisa, num prazo de 30 dias, utilizando-se a carta resposta .

\section{RESULTADOS/DISCUSSÕES}

As cartas foram enviadas pelo correio a todos os sócios da Sociedade Brasileira de Pediatria e Neonatologia não especificando área de atuação: pediatria ou neonatologia, em função do arquivo do Banco de Dados da Sociedade, mas obtivemos resposta apenas dos enfermeiros ligados ao atendimento à criança em unidade de pediatria. Portanto todos os participantes deste estudo realizam suas atividades assistenciais com a criança.

Foram devolvidos 30 questionários devidamente respondidos com respectivo Termo Livre Esclarecido assinado mostrando interesse em participar obedecendo assim os aspectos legais da pesquisa.

Para apresentação dos resultados a amostra ficou constituída de 30 enfermeiros. Sendo que destes 30 enfermeiros que atuam em pediatria, 17 estavam vinculados à área hospitalar, um à área ambulatorial e 12 à atenção básica de saúde. 
Ao perguntar sobre a classificação da instituição em relação à categoria profissional percebemos maior número de hospitais privados (10) seguido de estaduais (7), federais( 6) e municipais (1). Totalizando 24 hospitais. Destes apenas 19 responderam sobre a existência de unidade de internação pediátrica na instituição. Dos 19 hospitais apenas 13 (72,2\%) possuem brinquedoteca e cinco $(27,8)$ apesar da obrigatoriedade sobre a instalação das mesmas na instituição ${ }^{(9)}$, não contam com este recurso. Portanto os resultados discutidos neste estudo correspondem aos dados dos enfermeiros dos 13 hospitais que possuem brinquedoteca.

Ao serem questionados sobre o horário de funcionamento das brinquedotecas houve predomínio no horário da manhã e tarde em um total de 10 instituições $(76,9 \%)$, sendo as demais nos três períodos: manhã, tarde e noite $(23,1 \%)$. Pela importância do brincar na vida da criança estes dados nos sugere novos estudos que mostre a necessidade de se ter uma brinquedoteca com funcionamento nas 24 horas para que a criança possa brincar quando sentir necessidade e não apenas com atividades direcionadas.

Em relação à composição dos brinquedos utilizados nas brinquedotecas das instituições de saúde brasileiras estudadas, conforme resultados da Tabela 1 houve predomínio dos brinquedos cuja composição é de plástico, seguido daqueles a base de madeira. Apesar da dificuldade de métodos de higienização de objetos inanimados das mais variadas composição, percebe-se que alguns hospitais possuem o brinquedo composto de madeira disponível como objeto de uso individual e coletivo. ( falta referencia)

Tabela 1 - Distribuição de brinquedos segundo sua composição

\begin{tabular}{lcc}
\hline \multicolumn{1}{c}{ MATERIAL } & INSTITUIÇÃ \\
& N & $\%$ \\
\hline Plástico & 2 & 16,7 \\
Madeira & 0 & 00,0 \\
Acrílico & 0 & 00,0 \\
Tecido & 0 & 00,0 \\
Borracha & 0 & 00,0 \\
Metal & 0 & 00,0 \\
Pelúcia & 0 & 00,0 \\
Plástico/Madeira & 2 & 16,7 \\
Plástico/Madeira/Acrílico & 1 & 8,3 \\
Plástico/Madeira/Tecido & 2 & 16,7 \\
Plástico/Madeira/Acrílico/Tecido & 2 & 16,7 \\
Plástico/Madeira/Acrílico/Tecido/Borracha & 1 & 8,3 \\
Plástico/Tecido/Metal & 1 & 8,3 \\
Plástico/Tecido/Pelúcia & 1 & 8,3 \\
\hline Total & 13 & 100,0 \\
\hline
\end{tabular}

Ao serem indagados sobre o produto de higienização dos brinquedos em relação à composição do brinquedo; plástico e madeira, dos 13 enfermeiros apenas um não respondeu este item do questionário, conforme Quadro 1. Uma dado que nos chamou atenção foi que tanto os brinquedos que possem em sua composição o plástico ou madeira realizam a higienização com água e sabão seguido de álcool $70 \%$.

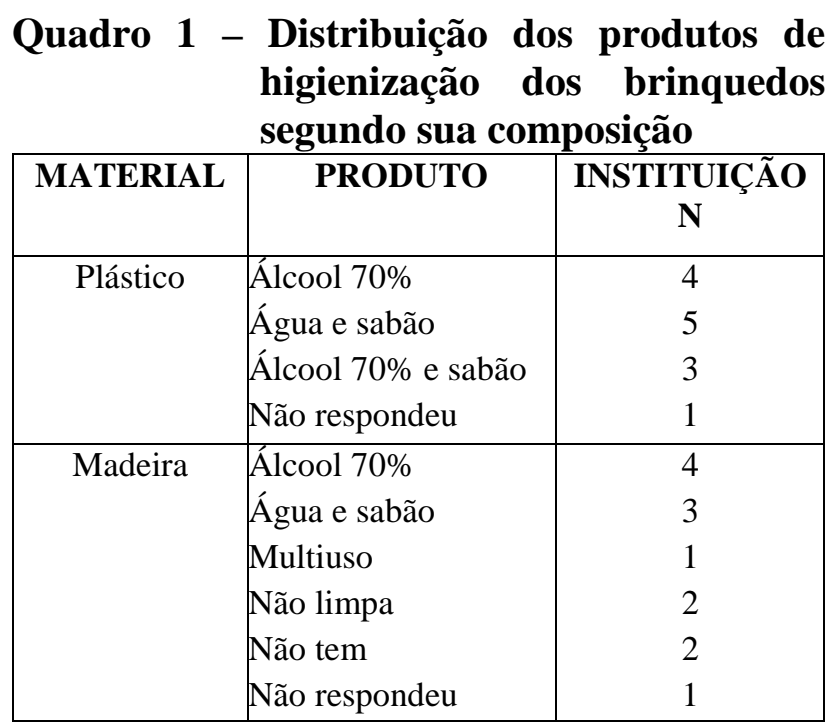


Dos 12 enfermeiros que responderam o item do questionário "Higienização dos brinquedos", percebe-se predomínio da higienização com o uso de pano úmido, conforme quadro 2 .

\begin{tabular}{|c|c|c|}
\hline \multicolumn{3}{|c|}{$\begin{array}{r}\text { Quadro2-Distribuição dos materiais } \\
\text { utilizados para higienização dos } \\
\text { brinquedos segundo a composição. }\end{array}$} \\
\hline MATERIAL & MATERIAL & \begin{tabular}{|c} 
INSTITUIÇÃO \\
$\mathbf{N}$
\end{tabular} \\
\hline Plástico & $\begin{array}{l}\text { Pano úmido } \\
\text { Esponja } \\
\text { Esponja seca } \\
\text { Fricção } \\
\text { Fricção com pano } \\
\text { Lavagem } \\
\text { Pia e torneira } \\
\text { Não Respondeu }\end{array}$ & $\begin{array}{l}3 \\
1 \\
1 \\
1 \\
1 \\
1 \\
1 \\
3\end{array}$ \\
\hline Madeira & \begin{tabular}{|l} 
Pano úmido \\
Esponja seca \\
Fricção \\
Fricção com pano \\
Imersão \\
Pia e torneira \\
Não respondeu
\end{tabular} & \begin{tabular}{l|l}
1 & \\
1 & \\
1 & \\
1 & \\
1 & \\
1 & \\
2 &
\end{tabular} \\
\hline
\end{tabular}

Das 12 instituições que possuem brinquedos de plásticos apenas dois enfermeiros, ou seja, duas instituições não informaram sobre a freqüência de higienização dos mesmos, no quadro 3 aponta para dois métodos mais freqüentes de higienização dos brinquedos de plástico nas brinquedotecas: diariamente $\mathrm{e}$ 1x/semana.

Quando indagamos os oito enfermeiros que possuem o brinquedo composto de madeira nas brinquedotecas em estudo, apenas cinco não informaram sobre a freqüência com que os mesmos são limpos. No quadro 03 mostra ainda que em relação aos brinquedos de composição a base de madeira não houve semelhança das freqüências de higienização nas instituições brasileiras pesquisadas.

\section{Quadro 03 - Distribuição das frequiências da} realização da higienização dos brinquedos segundo sua composição.

\begin{tabular}{|c|l|c|}
\hline MATERIAL & FREQUENCIA & $\begin{array}{c}\text { INSTITUIÇÃO } \\
\text { N }\end{array}$ \\
\hline Plástico & $1 \mathrm{x} /$ semana & 3 \\
& $2 \mathrm{x} /$ dia & 1 \\
& após uso & 2 \\
& diariamente & 3 \\
& $1 \mathrm{x} /$ mês & 1 \\
\hline Madeira & $1 \mathrm{x} /$ semana & 1 \\
& diariamente & 1 \\
& $2 \mathrm{x} /$ dia & 1 \\
& após uso & 1 \\
& se necessário & 1 \\
\hline
\end{tabular}

Apesar das recomendações da agencia nacional vigilância sanitária ${ }^{(13)}$, e considerando os dados estudados e a vivência enquanto enfermeira assistencial na área da criança e como docente observou a extrema relevância da profilaxia através do ato de higienização dos brinquedos. Uma vez que neste modo de transmissão de microrganismos estão envolvidos outros vetores: como superfícies e as mãos das próprias crianças, profissionais e os acompanhantes e familiares no ambiente hospitalar $^{(22-23,25,28,31,34)}$. Pesquisa sobre adesão ao uso de equipamentos de proteção $^{(38)} \mathrm{em}$ ambiente de centro cirúrgico conclui que os profissionais não aderiram a essa pratica mostrando mais uma vez a dificuldade dos profissionais na incorporação de condutas em relação a proteção em relação ao paciente e cuidador. Em outra pesquisa em relação à lavagem das mãos em unidade de internação pediátrica concluiu que há baixa adesão a lavagem das mãos principalmente antes da realização dos procedimentos ${ }^{(39)}$. Portanto este trabalho e novas investigações de grande 
relevância devido à possível disseminação de microrganismos, constituindo assim uma cadeia de transmissão na unidade de internação pediátrica entre o contato pelas mãos da equipe - criança - criança - acompanhante- brinquedo.

\section{CONCLUSÃO E CONSIDERAÇÕES FINAIS}

Este estudo sobre higienização de brinquedos mostra que ainda necessita de explorar por meio de novas investigações com numero maior de participantes para ter uma padronização dos métodos de higiene de acordo com a composição de o brinquedo no ambiente hospitalar. Transformando a realidade $\mathrm{e}$ minimizando as divergências entre a prática e o preconizado, proporcionando maior segurança e qualidade na assistência a saúde com o uso do brinquedo/brinquedo terapêutico e o ser humano envolvido.

\section{REFERÊNCIAS BIBLIOGRAFICAS}

1. Meirelles Neto JR, Gontijo Filho PP. Atividade tuberculicida de alguns detergentes catiônicos. Folha méd,1983; 87 (4):227-32.

2. Fernandes AT. Infecção Hospitalar e suas interfaces na área da saúde. São Paulo: Atheneu;2000. v.1.

3. Lacerda RA, Egry EY. As infecções hospitalares e sua relação com o desenvolvimento da assistência: reflexões para análise de suas práticas atuais de controle. Rev Latino-am Enfermag. 1997;5(4): 13-23.

4. Carraro TE. Os postulados de Nighintagale e Semmelweis: poder/vital e prevenção/contágio como estratégias para evitabilidade das infecções. Rev Latino-am Enfermag. 2004;12(4): 650-57.

5. Correa I. A importância da técnica das lavagens das mãos na formação do profissional enfermeiro. Enfermag Atual.2003;25-9.

6. Zanon U, Aguiar N, Costa BG. Diretrizes para a organização da comissão de controle de infecções hospitalares In: Zanon U, Neves J. Infecções hospitalares: prevenção, diagnóstico e tratamento.
Rio de Janeiro: Medsi;1987.

7. Rodrigues EAC. Histórico das infecções hospitalares. In: Rodrigues E A C, Mendonça JS, Amarante JMB , Alves Filho MB, Grinbaum,RS, Richtmann R. Infecções hospitalares: prevenção e controle. Sarvier: São Paulo; 1997.p.3-27.

8. Brasil. Ministério da Saúde. Portaria ${ }^{\circ} 2616$, de 12 de maio de 1998. Resolve expedir, na forma dos anexos I,II,III, IV e V, diretrizes e normas para a prevenção e o controle das infecções hospitalares, ficando revogada a portaria $\mathrm{n}^{\circ} 930$. Diário Oficial da União. Brasília. 13, maio, Seção 1, p. 133-5.

9. Pereira MS . Infecção hospitalar no Brasil: um enfoque sobre o seu controle. [Dissertação]. Ribeirão Preto: Escola de Enfermagem, USP; 1987.

10. Brasil. Ministério da Saúde. Secretaria Nacional de Organização e Desenvolvimento de Serviços de saúde. Manual de controle de infecção hospitalar. Brasília; 1987.

11. Brasil. Ministério da Saúde. Portaria n 196 de 24 de junho de 1983. Dispõe sobre as normas técnicas sobre a prevenção de infecções hospitalares. Diário Oficial da União. Jun. 1983. Seção 1, p.11. 319-23.

12. Brasil. Ministério da Saúde. Portaria $n^{\circ} 930$ de 27 de agosto de 1992. estabelece normas para o controle de infecção hospitalar e revoga a Portaria n. 196. Diário Oficial da União. 4 set 1992. Seção 1, p.12.279-81.

13. Brasil. Ministério da saúde. Lei n 9.431 de 6 de janeiro de 1997. Dispõe sobre a obrigatoriedade da manutenção de programa de controle de infecções hospitalares pelos hospitais do País. Diário Oficial da União. 7 jan 1997. Seção 1, p. 265.

14. Novaes LHVS, Isaacsson CB, Sandrini AH, Gruber GD, Gaspary LMB, Coghetto M, Talamonte VH. Brinquedo pode ser contagioso. Rev Paul Pediatr. 1997; 15: 77-81.

15. Correa I. Avaliação da ação antimicrobiano de dois desinfetantes hospitalares. [Dissertação]. Campinas Universidade Estadual de Campinas; 1988.

16. Marcondes E, Vaz FAC, Ramos JJA, Okay Y. Pediatria Básica -Tomo 1 Pediatria geral e neonatal, $9^{\mathrm{a}}$ ed São Paulo Savier,2002.

17. Cardoso MFS, Correa L, Medeiros ACT . A higienização dos brinquedos no ambiente hospitalar. Prát Hosp. 2005; 7 (42). 
18. Wong DL. Enfermagem pediátrica: elementos essenciais à intervenção efetiva. $5^{\mathrm{a}} \mathrm{ed}$. Rio de Janeiro Guanabara; 1999.

19. Mitre, RM A, Gomes R. A promoção do brincar no contexto da hospitalização infantil como ação de saúde . Ciênc Saúde Coletiva. 2004; 9: 147154.

20. Presidência da República. Lei n 8069, de 13 de julho de 1990. Dispõe sobre o Estatudo da Criança e do adolescente e dá outras providências.[acesso 08 de nov 2006].

Disponível em:

http://www.planalto.gov.br/ccivil/LEIS/L8069.ht $\underline{\mathrm{m}}$.

21.Sigaud, CHS, Rossato, LM, Rezende MA, Ângelo M, Veríssimo MDLO, Robeiro MO, Enfermagem Pediátrica -o cuidado de enfermagem à criança e ao adolescente, São Paulo EPU, 1996.

22. Falcin DC, Grandim LM, Dahmen M, Pina TA. $\mathrm{O}$ brinquedo na abordagem histórico-cultural. [ acessado em: 21 de out 2006]. Disponível em: http://www.lite.fae.unicamp.br/cursos/ep127/bri nq.htm

23. Poletto RC. A ludicidade da criança e sua relação com o contexto familiar. Psicol. Estud. 2005; 10: 67-75.

24. Motta AB, Emuno SRF. Brincar no hospital; estratégia de enfrentamento da hospitalização infantil Psicol Estud. 2004; 9: 19-28.

25. COREN - Conselho Regional de Enfermagem de São Paulo.Resolução Cofen n 295/2004. Coren-SP. 2004; 54.

26. Brasil, Ministério da Saúde. Portaria n 2261. Aprova o Regulamento que estabelece as diretrizes de instalação e funcionamento das brinquedotecas nas unidades de saúde que ofereçam atendimento pediátrico em regime de internação. Diário Oficial 24 de novembro de 2005, Seção 1, n 225.

27. Correa I. Avaliação do procedimento da lavagem das mãos no plano assistencial à criança portadora de diarréia aguda bacteriana. [Doutorado]. Universidade Estadual de Campinas; 1995.

28. Correa I, Ranali J, Pignatari ACC. Observação do Comportamento dos profissionais em relação ao procedimento da lavagem das mãos no plano assistencial à criança internada. Rev Téc Enfermag Nurs. ano 4, n/42, novembro de 2001.

29. Correa I, Ranali J , Pignatari ACC. Avaliação da eficácia de dois produtos comerciais utilizados na lavagem das mãos no hospital das clinicas. Ver Téc Enfermagem Nurs. 2005; 52: 15-21

30. Cardoso MFS, Corrêa L, Mederiros ACT. Prát Hosp. Infectologia. 2005. [acesso 04 out 2006]421: 1-5. Disponível em:http://www.praticahospitalar.com.br/ptratica \%2042/pags/materia\%2029-42.html.

31. Buttery JP et al. Multiresistent pseudomonas aeruginosa outbreak in a pediatric oncology ward related to bath toys. Pediatr Infect Dis. 1998; 17: 509-13.

32. Smalheiser RN. Bath toys - A source of gastrointestinal infection. N Engl J Med. 2004 Jan; 350:521.

33. Merriman E et al. Toys are a potencial sauce of cross-infection in general practitioners waiting rooms. Br J Genet Pract.. 2002; 52(475):287-90.

34. Àvila-Aguero ML et al.. Toys in a pediatric hospital: are they a bacterial source?

American J od Infect Control. 2004; 32:287-90.

35. Mckay I et al. Bacterial contamination of children's toys used in a general practitioner' $\mathrm{s}$ surgery . Scott Med J. 2000; 45: 12 -3.

36. Costa Neto, PL O. Estatística. São Paulo: Edgard Blücher:; 2000.

37. Pereira MS, Morya TM, Gir E. Infecção hospitalar nos hospitais: uma análise sobre seu controle. Rev latino-americana Enfermag, Ribeirão Preto, 1996, v.4 n.1.

38. Tipple AFV, Aguliari, HT, Souza ACS, Pereira MS, Mendonça ACC, Silveira C. Equipamentos de proteção em centros de material e esterilização: disponibilidade, uso e fatores intervenientes à adesão. Cienc cuid saúde. 2007; 6(4): 441-8.

39. Corrêa I, Nunes IMM. Higienización de lãs mãos. El cotidiano del profesional de la salud em uma unidad de internación pediátrica. Invest Educ Enferm. 2011; 29(1): 54-60. 